\title{
Pre-Earthquake Early Warning System
}

\author{
Drasti Chauhan \\ Department of Computer \\ Engineering, SSASIT \\ Surat, India
}

\author{
Kashyap Dobariya \\ Department of Computer \\ Engineering, SSASIT \\ Surat, India
}

\author{
Pratik Gadhiya \\ Department of Computer \\ Engineering, SSASIT \\ Surat, India
}

\author{
Bhavin Dhamecha \\ Department of Computer \\ Engineering, SSASIT \\ Surat, India
}

\begin{abstract}
Natural disasters and accidents are one bad truth of human civilization. One may not have a total control over it but one can reduce the vast effect of this catastrophe if one is well informed. So, we thought of making an App which will be helpful in this worst situation to minimize the aftermath.

The android App will be helpful majorly in the time of Earthquake and can be used as a medium to inform. Also, it will provide the information regarding other Natural disastrous events like cyclone, tsunami, flood, forest fire, etc. In case of natural calamity, we will be using the statistical analysis and will be able to locate the epicenter, responsible for the cause. Upon receiving the alerts about the natural calamity on the remote server, the server will compute whether to inform rest of the App users or not depending upon the result of the analysis performed by our algorithm. If the algorithm result comes out to be true, other App users of that area / location will be informed in no time and thousands of lives can be saved from all these Catastrophe and hence the name "Devastation Assist".
\end{abstract}

\section{Keywords}

Disasters, Earthquake, Safety, Panic Alert, Weather, Precautions, Seismograph.

\section{INTRODUCTION}

Natural disasters and accidents are one bad truth of human civilization. Natural calamities like earthquake are said to be the most destructive and unpredictable force. So, to reduce its destruction some steps should be executed. Also, calamities like floods, cyclonic storms, and tornadoes are predictable to some extent but earthquake is said to be unpredictable. One may not have a total control over it but one can reduce the vast effect of this catastrophe if one is well informed.

\subsection{Objectives of Devastation Assist}

Our objective is to make lives safe by informing them about to disastrous force moving towards them. If one gets informed before some time, large destruction can be achieved to apply this idea. We are working to make an android application will have modules that are capable to rescue, also provide precaution and will save lives.

\subsection{Current Situations}

No application is providing this all functionalities, only news and information related applications are available.

\subsection{Advantages of Devastation Assist}

1. The App will be free to use anywhere in the world.

2. App size will be small and easy to install because all the data will be on a centralized server.

3. Multiple admins can be created so it can be operated in different in time zone.

\subsection{Problem Specification}

1. GPS

2. Smart Phone

3. Internet Access

4. Server

\subsection{Proposed System Module}

The Devastation assist system will be helpful in any sort of catastrophe. Its main purpose is fast and accurate flow of information, help and rescue operation under adverse situation. As we know that the death rate and the number of casualties increases if right information is not able to reach in right (short) time. So, we thought of creating System of Web and App which will help achieve this.

\section{FEATURES}

\subsection{Panic Button}

In case of an earthquake or sudden surge of water due to any natural or manmade disaster, the user will just press the panic button in order to tell the near ones that to keep themselves in safe condition. The system will be equipped with manual and system algorithm to stop fake or false information flow.

\subsection{I am Safe Functionality}

In any adverse condition if the user click on the I'm safe button, the system will automatically detect the common friends depending upon the common phone numbers between the devices and all the common app users will get notified that this particular user is safe and can get their location as well.

\subsection{Emergency Contacts Number (Location Wise)}

As the user will install the app, the app will take GPS location and can serve the emergency contact numbers automatically whenever the user opts for this functionality. User can also get the emergency contact numbers by manually changing the city, by default it will fetch the emergency numbers of current location.

\subsection{Newsfeed}

In this section, the users will able to get all the latest news of the natural disaster around the world. Along with it, by clicking on the news, it will provide its location on Google maps. User can also fetch the news by specifying the date. To get more information about the related news user can jump to USGS website [6].

\subsection{Rescue Videos and Tips Section}

In this section, the user would be able to see all the collection of videos which can be useful in adverse conditions or in rescue operations. There will be videos and tips on first aid 
operations. How to give handle severely injured person. How to act and react in different natural or manmade calamity.

\section{LITERATURE REVIEW}

A literature review is a thing which include the current knowledge including theoretical and methodological contribution to the system in real world. There are some related applications like Natural Disaster Monitor, My Earthquake Alerts, India Earthquake Alerts, Earthquake Network-Real Time Alerts, Lastquake etc.

\subsection{Natural Disaster Monitor}

\subsubsection{Features}

- User can monitor natural disasters around the world.

- The icon color indicates the alert level-green, orange and red. The icon will look more transparent the older the event was published.

- Clicking on the item will bring up more details about the disaster event.

- UTM or geographic grids can optionally be displayed on the map.

\subsubsection{Limitations:}

- It only provides past disaster information.

- It doesn't predict early disaster. [1]

\subsection{My Earthquake Alerts}

\subsubsection{Features}

- Live earthquake information from all starts the world.

- $\quad$ Free push alerts customized for you, with no restrictions.

- Beautiful \& simple design, view earthquake on a map and in a list.

- Find the exact location, the depth and the distance away from you.

\subsubsection{Limitations}

- Information comes too late

- It doesn't provide any steps regarding security.

- Doesn't provide Emergency contacts. [2]

\subsection{India Earthquake Alerts}

\subsubsection{Features}

- Shows the latest earthquake in India with more than 3.0 magnitude.

- Provides filtration of earthquakes between start and end date.

- Alert and push notification of the last earthquake with more than 5.0 magnitude.

\subsubsection{Limitations}

- Doesn't provide quick information.

- Doesn't have I am safe feature.
- No news feed and emergency contacts section. [3]

\subsection{Earthquake Network- Real time alerts 3.4.1 Features}

- Real time detection of earthquake using network of smartphones.

- User report on felt earthquake.

- Earthquake data from national and international seismic networks.

- Earthquake warning seconds in advance.

\subsubsection{Limitations}

- Low graphics.

- $\quad$ PRO version required to get access to all features.

- Doesn't detect the minor earthquakes. [4]

\subsection{Lastquake \\ 3.5.1 Features}

- Real-time information and data.

- Customizable notifications (destructive earthquakes, earthquakes near user's location).

- Access to comments, photos and videos by witnesses.

- Allow the sharing of information on social media.

- Provides post-earthquake safety tips.

\subsubsection{Limitations}

- Missing many earthquakes on a real news.

- With android latest version, GPS on, the app cannot retrieve the current position. [5]

\section{OUR DISTINCTIVE FEATURES}

The first and foremost feature that separates this product from currently available products is that it offers PANIC ALERT i.e. when ever a user feels the minor jerk of pre-earthquake strokes he/she clicks the panic button and due to that server automatically pushes a notification to all the users currently in that particular area informing the chances of the earthquake and move to safe place if possible. This first notification will be unauthorized but after its authorized personality on server accredit it and then sends authorized notification to all the users. Another feature that makes our product unique is it comes with the I AM SAFE functionality which facilitates our user with enabling them to inform their loved ones that they are safe at particular place. Also, this feature proves to be the best because it works by sending text message to contacts that user has already entered at the time of sign up. Let's assume that parents of user don't use smart phone and, in this situation, also a user can inform their parents about their safety. Adding to it our data about natural calamities is dam precise due to USGS because we take all the updates related to disasters from United States Geological Services (USGS).

\section{IMPLEMENTATION}

Reviewing a brief literature and design literature, the Devastation Assist Application System is implemented in the Android Studio, SQL and Visual Studio. 

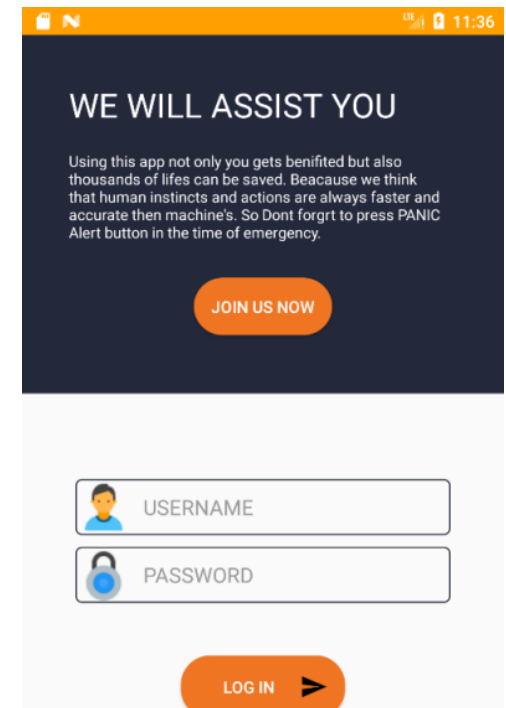

$\triangleleft$

O

$\square$

[Fig.1: Login Page]

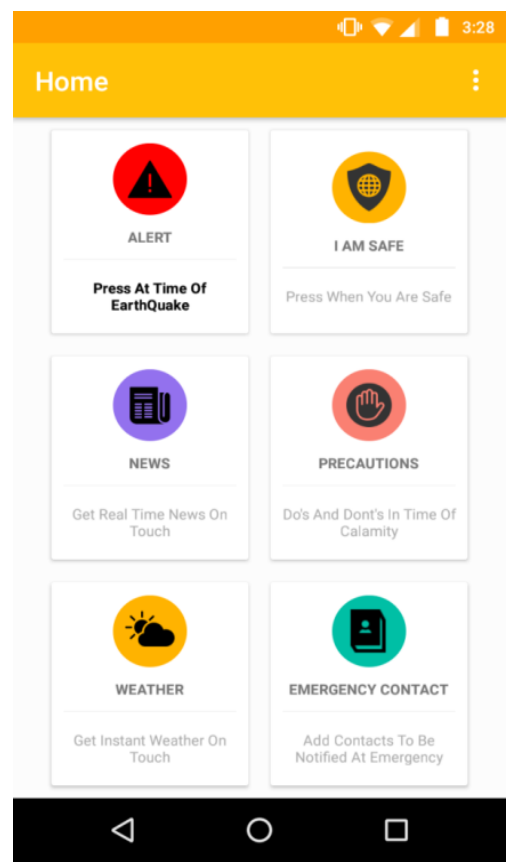

[Fig.2: Home Page]

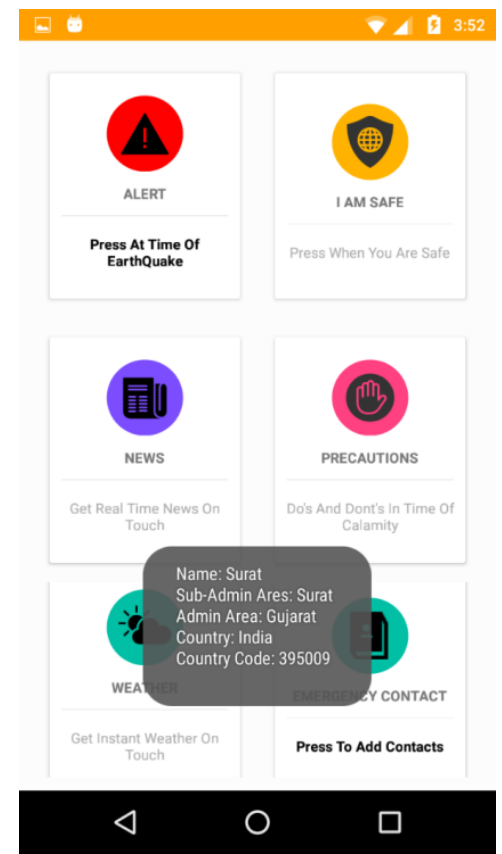

[Fig.3: Panic Alert] [11]

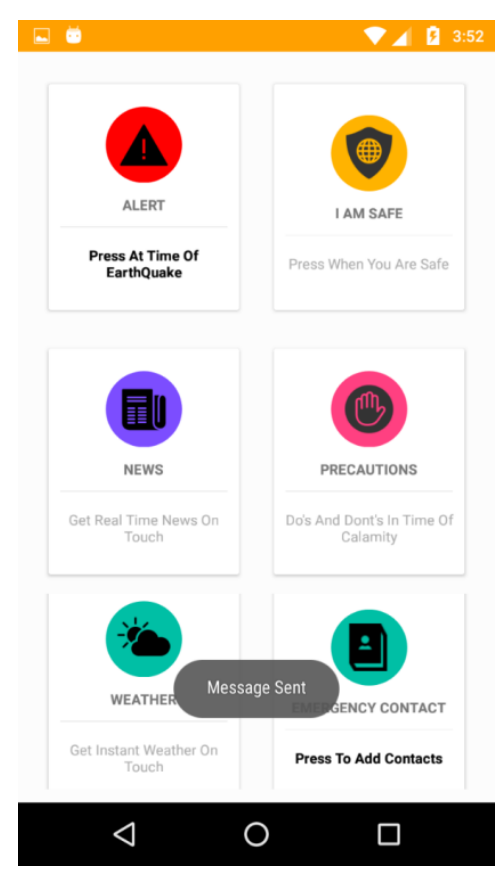

[Fig.4: I'm Safe] 


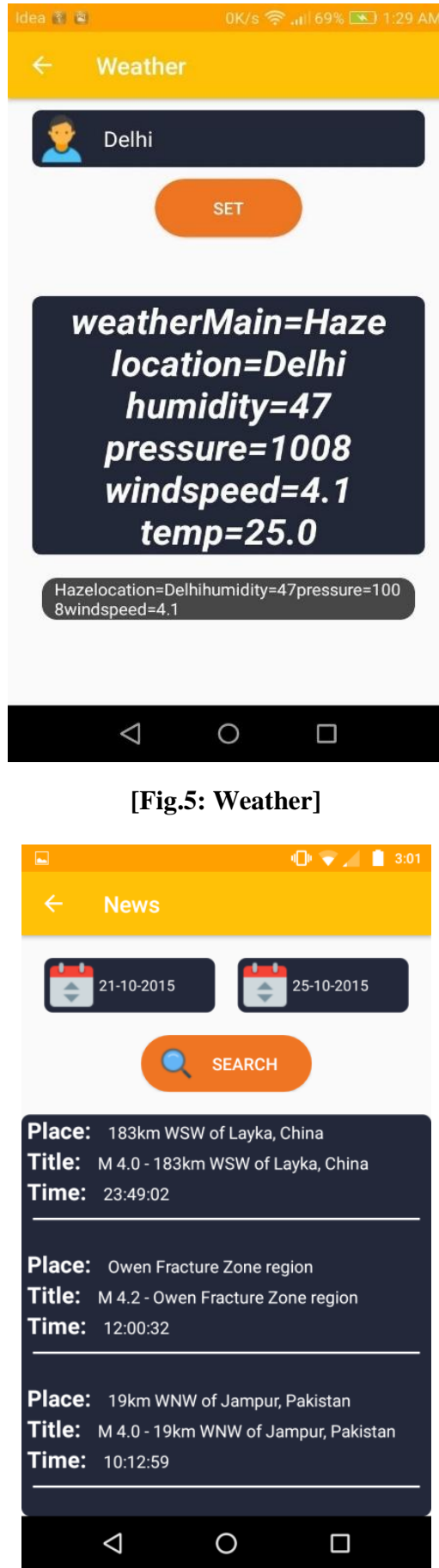

[Fig.6: Weather]

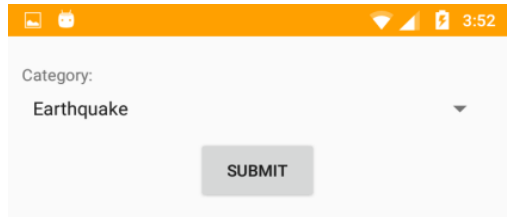

$\triangleleft$

O

$\square$

[Fig.7: Precautions]

\section{SUMMARY}

The main aim of this project is to build an application that will help the human kind to be alert before the earthquake occurs. As per the knowledge that before big earthquake arrives there are small jerks are experienced. Hence, after login we have main five modules in our app. First and foremost, the "panic alert" button which is pressed by the user if he/she feels any earthquake. As the certain number of users will press the button, in a particular area an unauthorized notification will be send to all the users of that particular area [11]. In a while, the admin will send same notification, but it will be authorized one. Secondly, there is a "I'm safe" module through which the user can send a SMS or message to their family members that he/she is safe. Thirdly, the user can be in touch with the latest news of the global village related to the earthquake by simply clicking on news and feed button and can also modify it by date(s) [6]. Moreover, the fourth module is about the weather. The user can get the weather information city-wise throughout the world. Last but not least, there is a module named "precaution" through which we can guide the users, how to be safe at the time of natural calamities [7].

\section{REFERENCES}

[1] Natural Disaster Monitor https://play.google.com/store/apps/details?id=com.dom 9 25.disastermon\&hl=en

[2] My Earthquake Alerts https://play.google.com/store/apps/details?id=com.jrusto napps.myearthquakealerts\&hl=en

[3] India Earthquake Alerts https://play.google.com/store/apps/details?id=doug.nasc.i ndiaalert

[4] Earthquake Network - Realtime alerts https://play.google.com/store/apps/details?id=com.finazz i.distquake\&hl=en

[5] LastQuake https://play.google.com/store/apps/details?id=org.emsc_c sem.lastquake\&hl=en 
[6] Earthquake Data from USGS (United States Geological Services).

https://www.google.co.in/search?q=USGS\&ie=utf$8 \& o e=u t f-8 \&$ client $=$ firefox $-b-$ ab\&gfe_rd=cr\&dcr=0\&ei=-bvBWoOeIfKvX5-trvAP

[7] Precaution to be taken in the time of earthquake. https://www.wikihow.com/React-During-an-Earthquake

[8] Android Application spinner guidelines taken from stake overflow.

https://stackoverflow.com/questions/10213015/how-tocapture-onclick-event-in-android-for-a-spinner

[9] Fetching user's current location help taken from stake overflow. https://stackoverflow.com/questions/17591147/how-toget-current-location-in-android

https://stackoverflow.com/questions/1513485/how-do-iget-the-current-gps-location-programmatically-inandroid

[10] Registration validation guidelines for android related applications for security.

http://www.vetbossel.in/registration-form-validationandroid/

[11] Google firebase for the notification purposes. https://firebase.google.com/docs/android/setup 